\title{
PENINGKATAN PRESTASI BELAJAR MATEMATIKA DENGAN MENGGUNAKAN TEKNIK DRILL KELAS IUPT SDN 07 SUNGAI DUO KECAMATAN SUNGAI PAGU KABUPATEN SOLOK SELATAN
}

\author{
ARMILA \\ Guru SD Negeri 07 Sungai Duo, Solok Selatan
}

\begin{abstract}
The progression of a nation is determined by the quality of the nation itself. To expedite the educational process, a forum or institution called a school is needed. They have systematically planned various environments, namely educational environments that provide various opportunities for students to carry out various learning activities so that students gain educational experiences. Thus, encouraging growth and development towards an aspired goal in education. In the process of teaching and learning activities, it is necessary to have a class management skill or skill that must be possessed by a teacher in delivering subject matter because each student has different abilities and levels of reasoning. For this reason, a teacher must be able to have the right approach and learning method so that students are able to understand the subject matter being taught. The purpose of this classroom action research (PTK) is to determine the extent to which the increase in mathematics learning achievement by applying drill techniques in class I UPT SDN 07 Sungai Duo, Pauh Duo District, South Solok Regency. In this classroom action research (CAR) is carried out in 3 cycles, the results of the actions taken are proven to improve student achievement by achieving ideal standards. From $60.09 \%$ in cycle I, it can increase to $70.09 \%$ in cycle II, and cycle III to $80.09 \%$. The results of this action research indicate that the application of the Drill Technique can improve student learning achievement by reaching $100 \%$ completeness.
\end{abstract}

Keywords: Student Achievement, Mathematics Learning, Drill Technique.

Abstrak: Maju mundurnya suatu bangsa ditentukan oleh kualitas bangsa itu sendiri. Untuk memperlancar proses pendidikan diperlukan suatu wadah atau lembaga yang disebut sekolah. Secara sistematis telah merencanakan bermacam lingkungan, yakni lingkungan pendidikan yang menyediakan bermacam kesempatan bagi siswa untuk melakukan berbagai kegiatan belajar sehingga siswa memperoleh pengalaman pendidikan. Dengan demikian, mendorong pertumbuhan dan perkembangannya kearah suatu tujuan yang dicita-citakan dalam pendidikan. Dalam proses kegiatan belajar mengajar diperlukan suatu keahlian atau keterampilan pengelolaan kelas yang harus dimiliki oleh seorang guru dalam menyampaikan materi pelajaran karena setiap siswa memiliki kemampuan dan taraf bernalar yang berbeda-beda. Untuk itu, seorang guru harus dapat memiliki pendekatan dan metode pembelajaran yang tepat agar siswa mampu memahami materi pelajaran yang diajarkan. Tujuan dari penelitian tindakan kelas (PTK) ini adalah untuk mengetahui sejauh mana peningkatan prestasi belajar Matematika denganmenerapkan teknik drill padasiswakelas I UPT SDN 07 Sungai Duo Kecamatan Pauh Duo Kabupaten Solok Selatan. Dalam penelitian tindakan kelas (PTK) ini dilakukan dalam 3 siklus, dari hasil tindakan yang dilakukan terbukti dapat meningkatkan prestasibelajar siswa dengan mencapai standar ideal. Dari 60,09\% pada siklus I, dapat meningkat menjadi 70,09 \% pada siklus II, dan siklus ke III 80,09 $\%$. Hasil penelitian tindakan ini menunjukkan bahwa penerapan Teknik Drilldapat meningkatkan prestasi belajar siswa dengan ketuntasan mencapai $100 \%$. 
Kata Kunci: Prestasi Belajar Siswa, Pembelajaran Matematika, Teknik Drill.

\section{A. Pendahuluan}

Pendidikan pada dasarnya merupakan proses untuk membantu manusia dalam mengembangkan dirinya sehingga mampu menghadapi setiap perubahan yang terjadi. Dalam rangka pembangunan manusia seutuhnya, pembangunan dibidang pendidikan merupakan sarana dan wahana yang sangat baik di dalam pembinaan Sumber Daya Manusia. Oleh karena itu, bidang pendidikan perlu mendapat perhatian, penanganan, dan prioritas secara intensif baik oleh pemerintah, keluarga, dan pengelola pendidikan khususnya. Maju mundurnya suatu bangsa ditentukan oleh kualitas bangsa itu sendiri. Untuk memperlancar proses pendidikan diperlukan suatu wadah atau lembaga yang disebut sekolah. Secara sistematis telah merencanakan bermacam lingkungan, yakni lingkungan pendidikan yang menyediakan bermacam kesempatan bagi siswa untuk melakukan berbagai kegiatan belajar sehingga siswa memperoleh pengalaman pendidikan. Dengan demikian, mendorong pertumbuhan dan perkembangannya kearah suatu tujuan yang dicita-citakan dalam pendidikan.

Belajar merupakan kegiatan bagi setiap orang. Pengetahuan dan keterampilan seseorang diperoleh melalui belajar. Keberhasilan proses dan hasil belajar dipengaruhi oleh dua faktor, yaitu faktor dari luar dan faktor dari dalam diri individu. Faktor dari luar yaitu faktor yang berasal dari luar diri anak/individu, terdiri dari lingkungan dan instrumental. Sedangkan faktor dari dalam yaitu faktor yang berasal dari dalam diri anak itu sendiri, terdiri dari faktor fisiologis dan psikologis. Matematika merupakan bidang studi yang dipelajari oleh semua siswa dari SD hingga SLTA dan bahkan juga Perguruan Tinggi jurusan IPA.Alasan Matematika perlu diajarkan kepada siswa karena Matematika banyak digunakan dalam segi kehidupan, dapat digunakan untuk menyajikan informasi dalam berbagai cara, meningkatkan kemampuan berpikir logis, ketelitian, dan kepuasan terhadap usaha memecahkan masalah yang menantang.

Menurut Paling (Mulyono Abdurrahman, 2003:252), ide manusia tentang Matematika berbeda-beda, tergantung pada pengalaman dan pengetahuan masingmasing. Ada yang mengatakan bahwa Matematika hanya perhitungan yang mencakup tambah, kurang, kali, dan bagi tetapi ada pula yang melibatkan topik-topik seperti aljabar, geometri, dan trigonometri. Banyak pula yang beranggapan bahwa Matematika mencakup segala sesuatu yang berkaitan dengan berpikir logis.Ciri utama Matematika adalah penalaran deduktif, yaitu kebenaran suatu konsep atau pernyataan diperoleh sebagai akibat logis dari kebenaran sebelumnya sehingga kaitan antar konsep dalam Matematika bersifat konsisten. Penalaran ini digunakan pada pola atau sifat untuk membuat generalisasi, memanipulasi Matematika, menyusun bukti, memberikan alasan,dan menarik kesimpulan. Dalam proses kegiatan belajar mengajar diperlukan suatu keahlian atau keterampilan pengelolaan kelas yang harus dimiliki oleh seorang guru dalam menyampaikan materi pelajaran karena setiap siswa memiliki kemampuan dan taraf bernalar yang berbeda-beda. Untuk itu, seorang guru harus dapat memiliki pendekatan dan metode pembelajaran yang tepat agar siswa mampu memahami materi pelajaran yang diajarkan.

Guru menyadari bahwa Matematika sering dianggap sebagai mata pelajaran yang kurang diminati, menjemuhkan, dan dihindari oleh sebagian besar siswa. Siswa seharusnya sadar bahwa kemampuan berpikir logis, bernalar rasional, dan cermat menjadi ciri utama Matematika. Penalaran adalah suatu proses berpikir dalam rangka menarik kesimpulan. Siswa yang mempunyai kemampuan bernalar tinggi tidak akan mengalami kesulitan dalam memahami materi pelajaran Matematika sebaliknya siswa 
yang kemampuan bernalarnya rendah mungkin akan mengalami kesulitan dalam memahami materi pelajaran Matematika.

Dewasa ini terlihat adanya upaya memperbaiki pembelajaran Matematika di jenjang persekolahan. Berbagai model dicoba untuk diterapkan dalam pembelajaran topik tertentu, yang tentunya bertujuan untuk meningkatkan mutu pendidikan Matematika salah satunya adalah Teknik drill yang merupakan suatu rangkaian kegiatan penyampaian materi pelajaran yang bertujuan memberi kesempatan kepada siswa untuk aktif belajar sehingga memungkinkan siswa memperoleh pengetahuan dan mengembangkan keterampilan kognitif dan manual, serta menumbuhkan kreatifitas siswa untuk memecahkan permasalahan yang dihadapi seperti bertanya terhadap sesuatu yang belum dipahami dengan menggunakan berbagai metode yang bervariasi untuk menciptakan suasana peserta didik dan mewujudkan pencapaian hasil belajar yang tinggi.

\section{B. Metodolgi Penelitian}

Penelitian ini merupakan penelitian tindakan kelas, yang dilakukan di UPT SDN 07 Sungai Duo Kecamatan Pauh Duo Kabupaten Solok Selatan yang memiliki 6 kelas dengan jumlah siswa relatif besar dibandingkan dengan SD lainnya yang ada di wilayah Kecamatan Pauh Duo. Penelitian dilakukan pada siswa kelas I, dengan jumlah siswa pada saat penelitian ini dilakukan terdiri dari 12 orang siswa $(\mathrm{P}=3 ; \mathrm{L}=9)$. Rancangan Penelitian dilaksanakan dalam 3 siklus pada semester Genap. Lama penelitian 6 pekan efektif dilaksanakan mulai tanggal 13 September sampai dengan 19 Oktober 2019.Dalam pelaksanaan tindakan, rancangan dilakukan dalam 3 siklus yang meliputi ; (a) perencanaan,(2) tindakan,(3) pengamatan,(4) refleksi.

Dalam penelitian tindakan kelas ini variabel yang diteliti adalah peningkatan prestasi belajar siswa pada mata pelajaran Matematika melalui penerapan teknik drillpada siswa kelas I UPT SDN 07 Sungai Duo Kecamatan Pauh Duo Kabupaten Solok Selatan. Variabel tersebut dapat dituliskan kembali sebagai berikut :

Variabel Harapan : Peningkatan prestasi belajar siswa pada pelajaran Matematika kelas I Pembelajaran melalui penerapan teknik drill.

\section{Variabel Tindakan :}

Sumber data dalam penelitian ini berasal dari dua sumber yaitu :

1 Siswa : Diperoleh data tentang Peningkatan prestasi belajar siswa pada pelajaran Matematika kelas I.

2 Guru : Diperoleh data tentang efektifitas penggunaan teknik drill.

Dalam pengumpulan data teknik yang digunakan adalah menggunakan observasi dan angket. Penelitian tindakan kelas yang dilaksanakan dalam tiga siklus dianggap sudah berhasil apabila terjadi peningkatan prestasi belajar siswa dalam pelajaran matematika apabila $85 \%$ siswa kelas 1 (kelas yang diteliti) telah mencapai ketuntasan dengan nilai rata rata 75. Jika peningkatan tersebut dapat dicapai pada tahap siklus 1 dan 2, maka siklus selanjutnya tidak akan dilaksanakan karena tindakan kelas yang dilakukan sudah dinilai efektif sesuai dengan harapan dalam kurikulum tingkat satuan pendidikan (KTSP). Teknik Analisis Data yang digunakan adalah ;Kuantitatif dan Kualitatif. Analisis Kuantitatif ini digunakan untuk menghitung besarnya peningkatan prestasi belajar siswa pada pelajaran Matematika menggunakan teknik drill dengan menggunakan prosentase (\%). Sedangkan Teknik Kualitatif digunakan untuk 
memberikan gambaran hasil penelitian secara ; reduksi data, sajian deskriptif, dan penarikan simpulan.

\section{Hasil dan Pembahasan}

Pelaksanaan kegiatan belajar mengajar untuk siklus I dilaksanakan pada tanggal 13 s/d 20 September 2019 di UPT SDN 07 Sungai Duo Kecamatan Pauh Duo Kabupaten Solok Selatan, dengan jumlah siswa 12 orang. Dalam hal ini peneliti bertindak sebagai guru. Adapun proses belajar mengajar mengacu pada rencana pelajaran yang telah dipersiapkan. Pengamatan (observasi) dilaksanakan bersamaan dengan pelaksaaan belajar mengajar. Pada akhir proses belajar mengajar siswa diberi tes formatif I dengan tujuan untuk mengetahui tingkat keberhasilan siswa dalam proses belajar mengajar yang telah dilakukan. Adapun data hasil penelitian pada siklus I pada tabel berikut :

Tabel 1 :

Distribusi Hasil Tes Pelajaran Matematika dengan Menggunakan Teknik drill pada Siklus I

\begin{tabular}{|c|c|c|c|c|c|}
\hline \multirow[b]{2}{*}{ No } & \multirow[b]{2}{*}{ Nama Siswa } & \multirow[b]{2}{*}{$\mathbf{L} / \mathbf{P}$} & \multirow{2}{*}{$\begin{array}{c}\text { Sko } \\
\mathbf{r}\end{array}$} & \multicolumn{2}{|c|}{ Keterangan } \\
\hline & & & & $\begin{array}{c}\text { Tunta } \\
\text { S }\end{array}$ & $\begin{array}{l}\text { Tidak } \\
\text { Tuntas }\end{array}$ \\
\hline 1 & Danda Utama & $\mathrm{L}$ & 70 & $\sqrt{ }$ & \\
\hline 2 & Diki Juliandra & $\mathrm{L}$ & 70 & $\sqrt{ }$ & \\
\hline 3 & Egi Afanda & $\mathrm{L}$ & 50 & & $\sqrt{ }$ \\
\hline 4 & Farel Dwi Firansyah & $\mathrm{L}$ & 50 & & $\sqrt{ }$ \\
\hline 5 & Jeri Suhanda & $\mathrm{L}$ & 50 & & $\sqrt{ }$ \\
\hline 6 & Radit Jamin Pratama & $\mathrm{L}$ & 50 & & $\sqrt{ }$ \\
\hline 7 & Abil Settiawan P & $\mathrm{L}$ & 50 & & $\sqrt{ }$ \\
\hline 8 & Amelda Putri & $\mathrm{P}$ & 60 & & $\sqrt{ }$ \\
\hline 9 & Alga Putri ananda & $\mathrm{P}$ & 60 & & $\sqrt{ }$ \\
\hline 10 & Abd Afdalel Husni & $\mathrm{L}$ & 65 & $\sqrt{ }$ & \\
\hline 11 & Alfan Setia Buana & $\mathrm{L}$ & 60 & & $\sqrt{ }$ \\
\hline 12 & Bunga Febrianti. S & $\mathrm{P}$ & 65 & $\sqrt{ }$ & \\
\hline \multicolumn{2}{|c|}{ Jumlah Total } & 12orang & 700 & - & - \\
\hline \multicolumn{2}{|c|}{ Skor Maksimum Individu } & - & 100 & - & - \\
\hline \multicolumn{2}{|c|}{ Skor maksimum Kelas } & - & 1200 & - & - \\
\hline
\end{tabular}

Keterangan :

Jumlah siswa yang tuntas

Jumlah siswa yang belum tuntas

Klasikal
:4 Orang

: 8 Orang

: belum tuntas

Dari tabel di atas dapat dijelaskan bahwa dengan menerapkan teknik drill diperoleh nilai rata-rata prestasi belajar siswa adalah 58,33\%. atau ada 4 siswa dari 12 siswa yang sudah tuntas. Hasil tersebut menunjukkan bahwa pada siklus pertama secara klasikal siswa belum tuntas belajar, karena siswa yang memperoleh nilai $\geq 65$ hanya sebesar 53,55 \%, lebih kecil dari persentase ketuntasan yang dikehendaki yaitu sebesar $85 \%$. Hal ini disebabkan karena siswa masih merasa baru dan belum mengerti apa yang dimaksudkan dan digunakan guru dengan menerapkan teknik drill.

Pelaksanaan kegiatan belajar mengajar untuk siklus II dilaksanakan pada tanggal 27 September s.d 05 Oktober 2018 di UPT SDN 07 Sungai Duo Kecamatan Pauh Duo Kabupaten Solok Selatan. Dalam hal ini peneliti bertindak sebagai guru. Adapun 
proses belajar mengajar mengacu pada rencana pelajaran dengan memperhatikan revisi pada siklus I, sehingga kesalahan atau kekurangan pada siklus I tidak terulang lagi pada siklus II. Pengamatan (observasi) dilaksanakan bersamaan dengan pelaksanaan belajar mengajar. Pada akhir proses belajar mengajar siswa diberi tes formatif II dengan tujuan untuk mengetahui tingkat keberhasilan siswa dalam proses belajar mengajar yang telah dilakukan. Instrumen yang digunakan adalah tes formatif II. Adapun data hasil penelitian pada siklus II adalah sebagai berikut;

Tabel 2 :

Destribusi Hasil Tes Pelajaran Matematika dengan menerapkan teknik drill pada Siklus II

\begin{tabular}{|c|c|c|c|c|c|}
\hline \multirow[b]{2}{*}{ No } & \multirow[b]{2}{*}{ Nama Siswa } & \multirow[b]{2}{*}{$\mathbf{L} / \mathbf{P}$} & \multirow[b]{2}{*}{ Skor } & \multicolumn{2}{|c|}{ Keterangan } \\
\hline & & & & Tuntas & $\begin{array}{c}\text { Tidak } \\
\text { Tuntas }\end{array}$ \\
\hline 1 & Danda Utama & $\mathrm{L}$ & 80 & $\sqrt{ }$ & \\
\hline 2 & Diki Juliandra & $\mathrm{L}$ & 80 & $\sqrt{ }$ & \\
\hline 3 & Egi Afanda & $\mathrm{L}$ & 60 & & $\sqrt{ }$ \\
\hline 4 & Farel Dwi Firansyah & $\mathrm{L}$ & 60 & & $\sqrt{ }$ \\
\hline 5 & Jeri Suhanda & $\mathrm{L}$ & 60 & & $\sqrt{ }$ \\
\hline 6 & Radit Jamin Pratama & $\mathrm{L}$ & 60 & & $\sqrt{ }$ \\
\hline 7 & Abil Settiawan P & $\mathrm{L}$ & 60 & & $\sqrt{ }$ \\
\hline 8 & Amelda Putri & $\mathrm{P}$ & 70 & $\sqrt{ }$ & \\
\hline 9 & Alga Putri ananda & $\mathrm{P}$ & 70 & $\sqrt{ }$ & \\
\hline 10 & Abd Afdalel Husni & $\mathrm{L}$ & 60 & & $\sqrt{ }$ \\
\hline 11 & Alfan Setia Buana & $\mathrm{L}$ & 70 & $\sqrt{ }$ & \\
\hline 12 & Bunga Febrianti. S & $\mathrm{P}$ & 75 & $\sqrt{ }$ & \\
\hline \multicolumn{2}{|c|}{ Jumlah Total } & 12Orang & 805 & - & - \\
\hline \multicolumn{2}{|c|}{ Skor Maksimum Individu } & - & 100 & - & - \\
\hline \multicolumn{2}{|c|}{ Skor maksimum Kelas } & - & 1200 & - & - \\
\hline
\end{tabular}

\section{Keterangan :}

Jumlah siswa yang tuntas

: 6 Orang

Jumlah siswa yang belum tuntas

Klasikal

: 6 Orang

: belum tuntas

Dari tabel di atas diperoleh nilai rata-rata prestasi belajar siswa adalah 67,08\% atau ada 6 siswa dari 12 siswa dengan ketuntasan $50 \%$. Hasil ini menunjukkan bahwa pada siklus II ini ketuntasan belajar secara klasikal telah mengalami peningkatan cukup lebih baik dari siklus I. Adanya peningkatan prestasi belajar siswa ini karena setelah guru menginformasikan bahwa setiap akhir pelajaran akan selalu diadakan tes sehingga pada pertemuan berikutnya siswa lebih termotivasi untuk belajar. Selain itu siswa juga sudah mulai mengerti apa yang dimaksudkan dan diinginkan guru dalam menerapkan teknik drill.Pelaksanaan kegiatan belajar pada siklus II ini masih terdapat kekurangan-kekurangan. Maka perlu adanya revisi untuk dilaksanakan pada siklus III.

Pelaksanaan kegiatan belajar mengajar untuk siklus III dilaksanakan pada tanggal 12 s.d 19 Oktober 2019 di UPT SDN 07 Sungai Duo Kecamatan Pauh Duo Kabupaten Solok Selatan dengan jumlah siswa 12 siswa. Dalam hal ini peneliti bertindak sebagai guru. Adapun proses belajar mengajar mengacu pada rencana pelajaran dengan memperhatikan revisi pada siklus II, sehingga kesalahan atau kekurangan pada siklus II tidak terulang lagi pada siklus III. Pengamatan (observasi) dilaksanakan bersamaan dengan pelaksanaan belajar mengajar. Pada akhir proses belajar mengajar siswa diberi 
tes formatif III dengan tujuan untuk mengetahui tingkat keberhasilan siswa dalam proses belajar mengajar yang telah dilakukan. Instrumen yang digunakan adalah tes formatif III. Adapun data hasil penelitian pada siklus III adalah sebagai berikut:

Tabel 3 :

Tabel Distribusi Nilai tes Pelajaran Matematika dengan menerapkan model pembelajaran Predict-Observe-Explain (POE)Pada Siklus III

\begin{tabular}{|c|l|c|c|c|c|}
\hline \multirow{2}{*}{ No } & \multirow{2}{*}{ NAMA SISWA } & & \multirow{2}{*}{ Skor } & \multicolumn{2}{|c|}{ Keterangan } \\
\cline { 5 - 6 } & & L/P & & Tuntas & $\begin{array}{c}\text { Tidak } \\
\text { Tuntas }\end{array}$ \\
\hline 1 & Danda Utama & L & 90 & $\sqrt{ }$ & \\
\hline 2 & Diki Juliandra & L & 90 & $\sqrt{ }$ & \\
\hline 3 & Egi Afanda & L & 80 & $\sqrt{ }$ & \\
\hline 4 & Farel Dwi Firansyah & L & 80 & $\sqrt{ }$ & \\
\hline 5 & Jeri Suhanda & L & 90 & $\sqrt{ }$ & \\
\hline 6 & Radit Jamin Pratama & L & 70 & $\sqrt{ }$ & \\
\hline 7 & Abil Settiawan P & L & 80 & $\sqrt{ }$ & \\
\hline 8 & Amelda Putri & P & 85 & $\sqrt{ }$ & \\
\hline 9 & Alga Putri ananda & P & 80 & $\sqrt{ }$ & \\
\hline 10 & Abd Afdalel Husni & L & 85 & $\sqrt{ }$ & \\
\hline 11 & Alfan Setia Buana & L & 80 & $\sqrt{ }$ & \\
\hline 12 & Bunga Febrianti. S & P & 90 & $\sqrt{ }$ & \\
\hline \multicolumn{2}{|l|}{ Jumlah Total } & $\mathbf{1 2 o r a n g}$ & $\mathbf{1 0 0 0}$ & - & - \\
\hline \multicolumn{2}{|l|}{ Skor Maksimum Individu } & - & $\mathbf{1 0 0}$ & - & - \\
\hline \multicolumn{2}{|l|}{ Skor maksimum Kelas } & - & $\mathbf{1 2 0 0}$ & - & - \\
\hline
\end{tabular}

Keterangan :

Jumlah siswa yang tuntas

Jumlah siswa yang belum tuntas Klasikal
: 12 Orang

: - Orang

: belum tuntas

Berdasarkan tabel di atas diperoleh nilai rata-rata tes formatif sebesar 83,33\% dan dari 12 siswa telah tuntas secara keseluruhan. Maka secara klasikal ketuntasan belajar yang telah tercapai sebesar $100 \%$ ( termasuk kategori tuntas ). Hasil pada siklus III ini mengalami peningkatan lebih baik dari siklus II. Adanya peningkatan prestasi belajar pada siklus III ini dipengaruhi oleh adanya peningkatan kemampuan guru dalam menerapkan teknik drill sehingga siswa menjadi lebih terbiasa dengan pembelajaran seperti ini sehingga siswa lebih mudah dalam memahami materi yang telah diberikan. Di samping itu ketuntasan ini juga dipengaruhi oleh kerja sama dari siswa yang telah menguasai.

Pada siklus III guru telah menerapkan teknik drill dengan baik, dan dilihat dari aktivitas siswa serta prestasi belajar siswa pelaksanaan proses belajar mengajar sudah berjalan dengan baik. Maka tidak diperlukan revisi terlalu banyak, tetapi yang perlu diperhatikan untuk tindakan selanjutnya adalah memaksimalkan dan mempertahankan apa yang telah ada dengan tujuan agar pada pelaksanaan proses belajar mengajar selanjutnya dengan menerapkan teknik drill, dapat meningkatkan proses belajar mengajar sehingga tujuan pembelajaran dapat tercapai. Setelah dilakukan tindakan pada siklus 1, siklus 2 dan siklus 3 menunjukkan hasil sebagai berikut: 


\section{Tabel 4 :}

Analisis Hasil Tes Pembelajaran Matematika menerapkan teknik drillSebelum dan Sesudah Diberi Tindakan

\begin{tabular}{|c|l|c|c|c|}
\hline No & \multicolumn{1}{|c|}{ Nama Siswa } & $\begin{array}{c}\text { Skor sebelum } \\
\text { Tindakan } \\
\text { Siklus 1 }\end{array}$ & $\begin{array}{c}\text { Skor setelah } \\
\text { Tindakan 1 }\end{array}$ & $\begin{array}{c}\text { Skor setelah } \\
\text { Tindakan 2 }\end{array}$ \\
\hline 1 & Danda Utama & 70 & 80 & Siklus 3 \\
\hline 2 & Diki Juliandra & 70 & 80 & 90 \\
\hline 3 & Egi Afanda & 50 & 60 & 90 \\
\hline 4 & Farel Dwi Firansyah & 50 & 60 & 80 \\
\hline 5 & Jeri Suhanda & 50 & 60 & 90 \\
\hline 6 & Radit Jamin Pratama & 50 & 60 & 70 \\
\hline 7 & Abil Settiawan P & 50 & 60 & 80 \\
\hline 8 & Amelda Putri & 60 & 70 & 85 \\
\hline 9 & Alga Putri ananda & 60 & 70 & 80 \\
\hline 10 & Abd Afdalel Husni & 65 & 75 & 85 \\
\hline 11 & Alfan Setia Buana & 60 & 70 & 80 \\
\hline 12 & Bunga Febrianti. S & 65 & 75 & 90 \\
\hline Jumlah Total & $\mathbf{7 0 0}$ & $\mathbf{8 0 5}$ & $\mathbf{1 0 0 0}$ \\
\hline Skor Maksimum Individu & $\mathbf{1 2 0 0}$ & $\mathbf{1 2 0 0}$ & $\mathbf{1 2 0 0}$ \\
\hline Skor Maksimum Kelas & & & $\mathbf{1 0 0}$ & \\
\hline
\end{tabular}

Berdasarkan hasil penelitian di atas, maka prestasi belajar siswa untuk pelajaran Matematika dengan menerapkan teknik drill hasilnya sangat baik. Hal itu tampak pada pertemuan dari 30 orang siswa yang hadir pada saat penelitian ini dilakukan nilai rata rata mencapai ; 58,33\%;67,08\%;83,33\%, Dari analisis data di atas bahwa pembelajaran dengan teknik drill dapat diterapkan pada pembelajaran Matematika kelas I, proses kegiatan belajar mengajar lebih berhasil dan dapat meningkatkan ketuntasan belajar siswa khususnya pada siswa kelas I di UPT SDN 07 Sungai Duo Kecamatan Pauh Duo, oleh karena itu diharapkan kepada para guru SD dapat melaksanakan pembelajaran dengan menggunakan teknik drill di kelas I. Berdasarkan Kurikulum Tingkat Satuan Pendidikan ( KTSP ) siswa dikatakan tuntas apabila siswa telah mencapai nilai standar ideal 75 mencapai $\geq 85 \%$. Sedangkan pada penilitian ini, pencapai nilai $\geq 75$ pada ( siklus 3 ) mencapai melebihi target yang ditetapkan dalam KTSP yaitu mencapai $100 \%$. Dengan demikian maka hipotesis yang diajukan dapat diterima.

\section{Penutup}

Pembelajaran dengan menerapkan teknik drill dapat meningkatkan prestasi belajar siswa di UPT SDN 07 Sungai Duo Kecamatan Pauh Duo pada mata pelajaran Matematika yang ditandai dengan peningkatan prestasi belajar siswa dalam setiap siklus, yaitu; 58,33\%;67,08\%;83,33\%. Penerapan teknik drill pada pelajaran Matematika mempunyai pengaruh positif, yaitu dapat meningkatkan ketuntasan belajar siswa. Penerapan teknik drill pada pelajaran Matematika efektif untuk meningkatkan kembali materi ajar yang telah diterima siswa selama ini, sehingga mereka merasa siap untuk menghadapi pelajaran berikutnya. 


\section{Daftar Pustaka}

Arikunto, Suharsimi.2007.Penelitian Tindakan Kelas. Jakarta : Remaja Rosdakarya Departemen Pendidikan dan Kebudayaan, 1988, Kamus Besar Bahasa Indonesia, Jakarta, Balai Pustaka.

Hudoyo, Herman. 1990. Strategi Mengajar Belajar Matematika. Malang: IKIP Malang

Indrawati, dkk.2009. Pembelajaran aktif, kreatif, efektif, dan menyenangkan untuk guru SD. Jakarta : PPPPTK Matematika Program BERMUTU.

Lie, Anita. 2002. Teknik Drill: Mempraktikkan Teknik Drill di Ruang-ruang Kelas. Jakarta: PT Gramedia Widiasarana Indonesia

Nur, Muhammad. 2000. Pengajaran Berpusat Pada Siswa dan Pendekatan Konstruktivis Dalam Pengajaran. Surabaya: UNESA

Raka Joni, T. 1985 Cara Belajar Siswa Aktif Implementasinya Terhadap Sistem Penyampaian, Jakarta P2LPTK Ditjen Dikti Depdikbud (*).

Raka Joni, T. 1985b. Teknik Belajar-Mengajar: Suatu Tinjauan Pengantar. Jakarta;: P2LPTK Ditjn Dikti Depdikbud. (*)

Sulo Lipu La Sulo, 1990. Strategi Belajar - Mengajar pada DII Pendidikan Guru Sekolah Dasar.Ujung Pndang: Penitia Penataran PKD PGSD, Proyek PTK, Ditjen Dikti, Depdikbud. 